\title{
Metabolic Acidosis in Patients with CKD: Epidemiology, Pathogenesis, and Treatment
}

\author{
Marcin Adamczak Stanisław Surma \\ Department of Nephrology, Transplantation and Internal Medicine, Medical University of Silesia in Katowice, \\ Katowice, Poland
}

\section{Keywords}

Metabolic acidosis · Chronic kidney disease · Sodium bicarbonate $\cdot$ Veverimer

\begin{abstract}
Background: Metabolic acidosis in CKD is diagnosed in patients with plasma or venous blood bicarbonate concentration lower than $22 \mathrm{mmol} / \mathrm{L}$. Metabolic acidosis occurs in about $20 \%$ of patients with CKD. Metabolic acidosis may lead to dysfunction of many systems and organs as well as CKD progression. Currently, sodium bicarbonate is mainly used for pharmacological treatment of metabolic acidosis in patients with CKD. Veverimer is a new drug dedicated to treatment of metabolic acidosis in patients with CKD. Orally given veverimer binds hydrogen ions in the intestines and subsequently is excreted from the body with feces. Clinical studies have shown that veverimer is effective in increasing serum bicarbonate concentrations in CKD patients with metabolic acidosis. Here, we present review of the epidemiology, pathogenesis, diagnosis, treatment, and prevention of metabolic acidosis in CKD patients. Summary: Metabolic acidosis is common in patients with CKD and contributes to CKD progression and many complications, which worsen the
\end{abstract}

karger@karger.com www.karger.com/kdd

Karger"
(C) 2021 The Author(s)

Published by S. Karger AG, Basel

This is an Open Access article licensed under the Creative Common Attribution-NonCommercial-4.0 International License (CC BY-NC) (http://www.karger.com/Services/OpenAccessLicense), applicable to the online version of the article only. Usage and distribution for commercial purposes requires written permission. prognosis in these patients. Currently, sodium bicarbonate is mainly used in metabolic acidosis treatment. The role of the new drug veverimer in the metabolic acidosis therapy needs further studies. Key Message: The aim of this review article is to summarize the current knowledge concerning the epidemiology, pathogenesis, diagnosis, treatment, and prevention of metabolic acidosis in CKD patients.

(c) 2021 The Author(s)

Published by S. Karger AG, Basel

\section{Acid-Base Homeostasis in Patients with CKD}

Maintenance of normal plasma hydrogen ion concentration depends on lung, kidney, liver, bone and gastrointestinal tract function. Under normal conditions, concentration of hydrogen ions in the plasma is 35-45 $\mathrm{nmol} / \mathrm{L}$, which corresponds to arterial blood $\mathrm{pH} 7.35$ 7.45. During $24 \mathrm{~h}$, an adult person with a body weight of $70 \mathrm{~kg}$ produces $15-20 \mathrm{~mol}$ of gaseous $\mathrm{CO}_{2}$ excreted by the lungs and $70 \mathrm{mmol}$ of nonvolatile hydrogen ions excreted by the kidneys $[1,2]$.

The bicarbonate/carbonic acid system forms the most important and the most capacious buffer in the body, rep- 
Fig. 1. Henderson-Hasselbalch equation. Based on $[1,2]$.
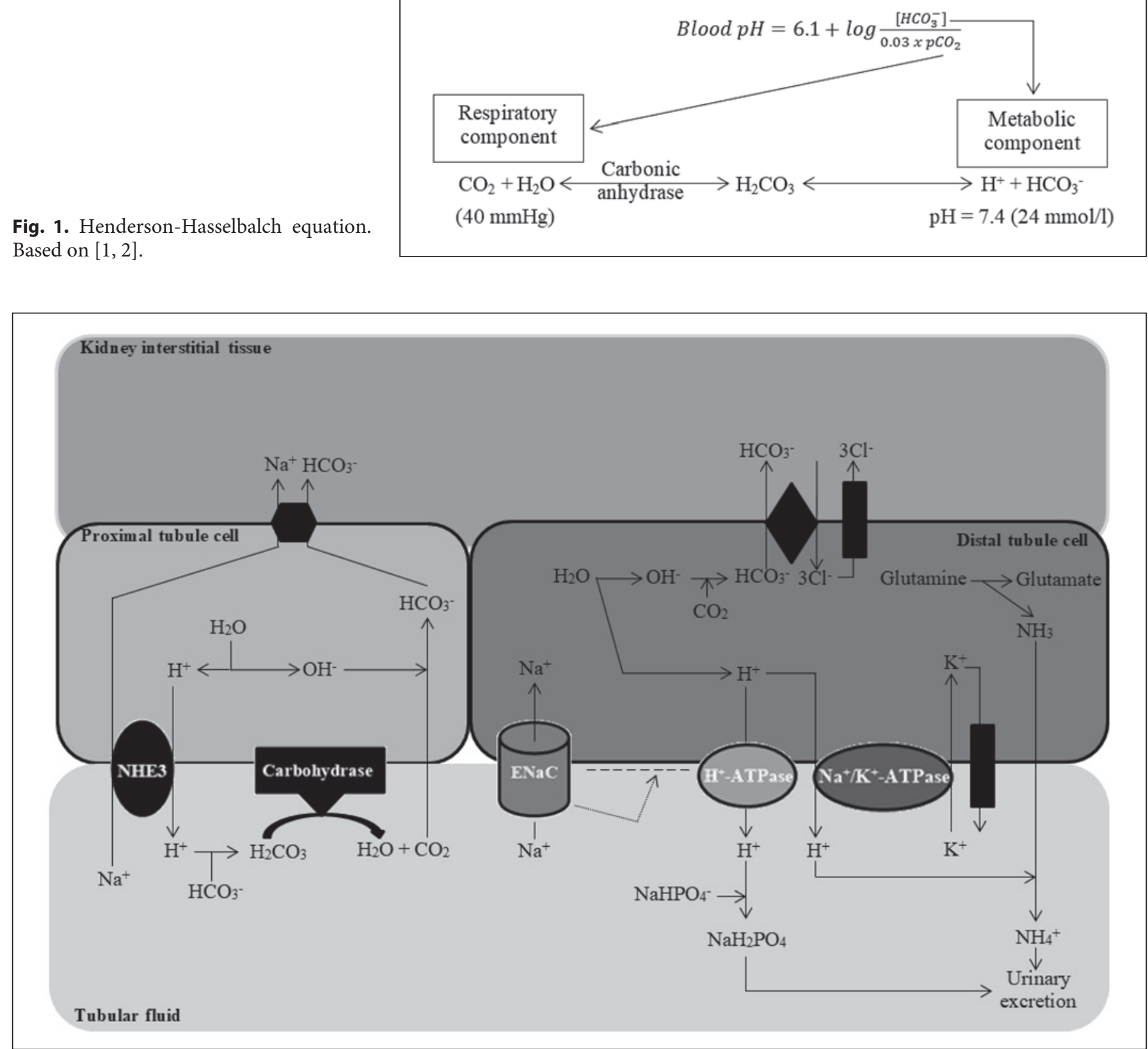

Fig. 2. Excretion of hydrogen ions by the kidneys. NHE3, the sodium-hydrogen antiporter 3; ENaC, epithelial sodium channel. Based on $[1,2]$.

resenting the majority of the blood buffer capacity. According to the Henderson-Hasselbalch equation (Fig. 1), maintaining physiological $\mathrm{pH}$ depends on $\mathrm{pCO}_{2}$, which in turn depends on alveolar ventilation (hypoventilation causes acidosis and hyperventilation causes alkalosis). The kidneys participate in maintaining the stable $\mathrm{pH}$ by reabsorption of bicarbonate $(3,600 \mathrm{mmol}$ of bicarbonate is filtrated in glomeruli during $24 \mathrm{~h}$ ) and excretion of hydrogen ions from nonvolatile acids (including sulfur and phosphate) as titratable acidity ( $0.3 \mathrm{mmol}$ hydrogen ions/ $\mathrm{kg} /$ day $)$ and in the form of ammonium ion $(0.7 \mathrm{mmol} \mathrm{hy}-$ drogen ions/kg/day) $[1,2]$.

Bicarbonate $\left(\mathrm{HCO}_{3}{ }^{-}\right)$reabsorption occurs in the kidneys in every part of the tubules. About $85-90 \%$ of the 
Fig. 3. Diagnosis of metabolic acidosis in patients with CKD. Based on [7].

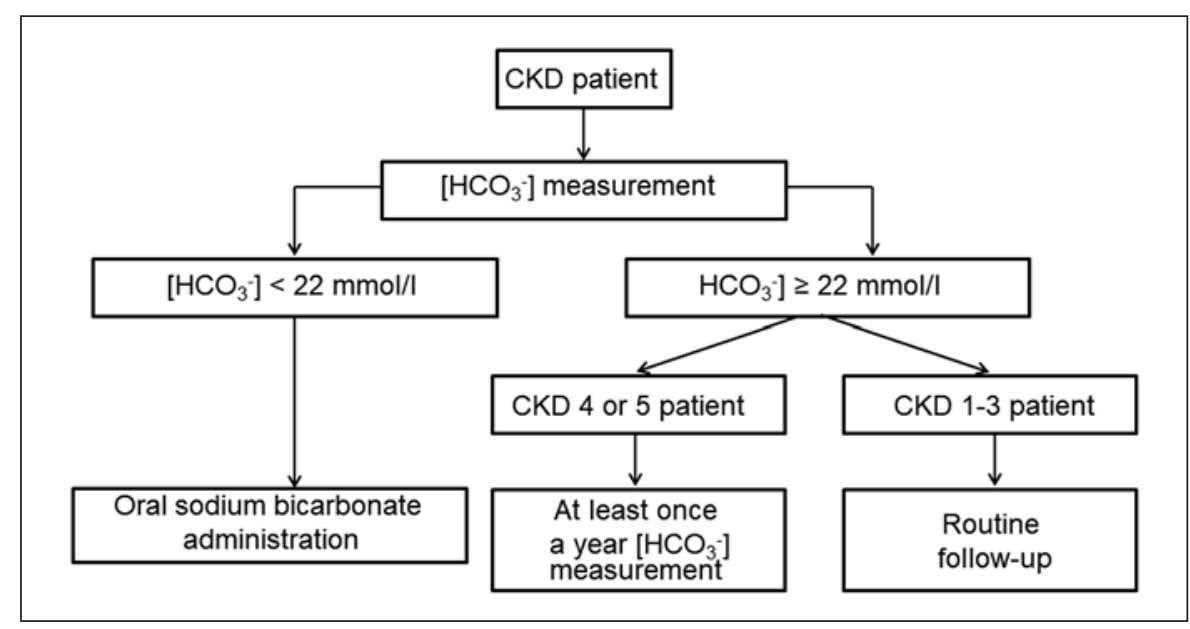

filtered bicarbonate is reabsorbed in the proximal tubules, $10 \%$ in the ascending arms of the Henle loop, $6 \%$ in the distal tubules, and $4 \%$ in the collecting tubules [ 1 , 2]. In the proximal tubule cells, the water molecule dissociates into hydrogen and hydroxyl ions. The hydrogen ion with the activity of a sodium-hydrogen antiporter 3 (NHE3) is exchanged for a sodium cation in the tubular fluid. The hydrogen ion is then combined with the filtered bicarbonate, which results in the formation of an unstable carbonic acid, which decomposes in the reaction catalyzed by membrane carbohydrase into carbon dioxide and water. Then, carbon dioxide diffuses into the cells of the proximal tubule and binds to the hydroxide anion (resulting from the dissociation of water) to form the bicarbonate anion. Finally, the bicarbonate passes into the blood (Fig. 2) [1, 2].

In the distal tubule, the regeneration of bicarbonate takes place through several mechanisms. Sodium cation in the tubular fluid is reabsorbed by the epithelial sodium channel into the cytoplasm of the distal tubule cells. As a consequence of this process, a negative charge is generated in the lumen of the distal tubule, which increases the activity of membrane ATP-ase $\mathrm{K}^{+} / \mathrm{H}^{+}$(its stimulation depends on the activity of epithelial sodium channel, aldosterone, angiotensin II, and calcium receptor activity). Increased ATP-ase $\mathrm{K}^{+} / \mathrm{H}^{+}$activity leads to secretion of hydrogen ions into the tubular fluid. The remaining hydroxide anions combine with carbon dioxide inside the tubular cells, resulting in the formation of bicarbonate, which then enter the blood. The hydrogen ion secreted into the tubular fluid combines with ammonia to form an ammonium ion or combines with $\mathrm{NaHPO}_{4}{ }^{-}$to form $\mathrm{NaH}_{2} \mathrm{PO}_{4}$ (as a titration acidity). Ammonium ion and $\mathrm{NaH}_{2} \mathrm{PO}_{4}$ are then excreted with urine (Fig. 2) [1, 2].
Summing up, the kidneys excrete excess acids in the form of titratable acidity and in the form of ammonium ions. It should be mentioned that in the case of increased acid load, the kidneys increase acid elimination mainly by increasing ammonium ion excretion [1-4]. Abnormalities occurring in the kidneys in the regeneration and reabsorption of bicarbonate and secretion of hydrogen ions into the tubular fluid are the main causes of tubular acidosis and metabolic acidosis in CKD $[1,2]$.

\section{Definition, Diagnosis, and Epidemiology of Metabolic Acidosis in CKD}

Metabolic acidosis (non-respiratory acidosis) in patients with CKD is an acid-base disturbance that occurs with a decrease in bicarbonate concentrations in plasma or venous blood below $22 \mathrm{mmol} / \mathrm{L}$. This threshold value for the diagnosis of metabolic acidosis in CKD was established based on the results of observational studies showing that CKD patients with plasma or venous blood bicarbonate concentrations below $21-23 \mathrm{mmol} / \mathrm{L}$ are characterized by increased CKD progression and higher mortality [5]. The results of the recently published intervention study the Use of Bicarbonate in Chronic Renal Insufficiency (UBI) may suggest that the threshold value for plasma or venous blood bicarbonate justifying the diagnosis of metabolic acidosis in CKD should be higher, that is, $24 \mathrm{mmol} / \mathrm{L}$ [6].

The incidence of metabolic acidosis obviously increases with decreasing glomerular filtration. The severity of metabolic acidosis in CKD is usually moderate, and plasma or blood bicarbonate concentrations are in the range of $12-22 \mathrm{mmol} / \mathrm{L}[7,8]$. 
Table 1. Recommendations for the diagnosis and treatment of metabolic acidosis in CKD patients formulated by the experts of the Working Group of the Polish Society of Nephrology on Metabolic and Endocrine Abnormalities in Kidney Diseases [7]

Measurement of bicarbonate concentration in venous plasma or venous blood to check for metabolic acidosis should be performed in all patients with CKD

In patients with CKD stage 4 or 5 (not yet on renal replacement therapy), the determination of venous plasma or venous blood bicarbonate concentration should be carried out at least once a year

Metabolic acidosis in patients with CKD should be diagnosed when the venous plasma or venous blood bicarbonate concentration is lower than $22 \mathrm{mmol} / \mathrm{L}$

In patients with metabolic acidosis and CKD, oral sodium bicarbonate administration is recommended

The goal of treatment of metabolic acidosis in patients with CKD is to achieve a plasma or blood bicarbonate concentration equal to or greater than $22 \mathrm{mmol} / \mathrm{L}$

In patients with plasma or blood bicarbonate concentrations of 19-21.9 mmol/L, the diagnosis should be confirmed by a second measurement [9]. In the diagnosis of metabolic acidosis in CKD, arterial blood collection is not recommended due to the risk of bleeding and local complications associated with arterial puncture and to avoid damage to the arterial wall (this may hinder the formation of an arteriovenous fistula in the future) [5,7]. The clinically useful diagnostic algorithm of metabolic acidosis in CKD proposed by experts of The Working Group of the Polish Society of Nephrology on Metabolic and Endocrine Abnormalities in Kidney Diseases is presented in Figure 3 and in Table 1 [7].

The prevalence of metabolic acidosis in CKD has been evaluated in many studies. In the CRIC study (Chronic Renal Insufficiency Cohort Study), which involved 3,939 patients with CKD stages 2-4, metabolic acidosis occurred in $17 \%$ of patients [10]. Skiba et al. [11] in a study with 500 patients with CKD stages $1-5$ showed that metabolic acidosis occurred in $20 \%$ of patients. In the recently published retrospective study of Kuczera et al. [12], the frequency of metabolic acidosis was analyzed in a group of 964 patients with CKD (698 with CKD at stages 1-5, 226 patients undergoing hemodialysis and 40 patients undergoing peritoneal dialysis). It has been shown that the frequency of metabolic acidosis increases with the stage of CKD [12]. In the study of Harambat et al. [13], in which 1,162 children and adolescents with CKD stages
3-5 were studied, it was shown that metabolic acidosis occurred in $43 \%$ of patients in stage 3,61\% in stage 4 , and $45 \%$ in stage 5 of CKD. The results of this study indicate a higher prevalence of metabolic acidosis in children and adolescents with CKD than in the adult CKD population [13]. On the other hand, Skiba et al. [11] showed that the frequency of metabolic acidosis in kidney transplant patients is lower than in patients with CKD (12 vs. 20\%). Kuczera et al. [12] showed that the initiation of dialysis therapy reduces prevalence of metabolic acidosis. In hemodialysis patients, the incidence of metabolic acidosis was lower than in patients with CKD stage 5 (39 vs. 56\%). The factors that may influence bicarbonate plasma concentration in hemodialysis patients are the bicarbonate transfer from dialysis fluid to plasma during hemodialysis procedure and patient's residual renal function, among others. The relation between residual renal function in hemodialysis patients and metabolic acidosis occurrence has not been studied so far.

Kuczera et al. [12] found that in comparison to hemodialysis patients, in patients undergoing peritoneal dialysis, the incidence of metabolic acidosis was significantly lower (3 vs. 39\%) (Fig. 4). A lower incidence of metabolic acidosis in CKD patients treated with peritoneal dialysis compared to those treated with hemodialysis was also demonstrated in the study by Goutham et al. [14]. In the study, the serum bicarbonate concentration in 100 hemodialysis patients and 41 peritoneal dialysis patients was assessed, and it was shown that metabolic acidosis occurred in $73 \%$ of hemodialysis patients and in $12 \%$ of peritoneal dialysis patients [14]. Similarly, Chang et al. [15] showed that among 441 patient treated with peritoneal dialysis, the frequency of metabolic acidosis was $4 \%$. The lower incidence of metabolic acidosis in patients treated with peritoneal dialysis than in those treated with hemodialysis seems to be due to several factors. Patients with CKD undergoing peritoneal dialysis are characterized by greater residual renal function $[16,17]$. Chang et al. [15] showed in peritoneal dialysis patients that there is a positive relationship between residual renal function and serum bicarbonate concentration. Moreover, peritoneal dialysis patients are less prone to hyperkalemia (due to high potassium elimination during peritoneal dialysis) [18]. It is well known that hyperkalemia leads to decrease in bicarbonate plasma concentration [19]. During peritoneal dialysis, high bicarbonate intake from the peritoneal dialysis fluid might also occurred $[14,15]$. All the abovementioned processes may be related to lower prevalence of metabolic acidosis in peritoneal dialysis patients than in hemodialysis patients. 
Fig. 4. Incidence of metabolic acidosis in patients with CKD or undergoing renal replacement therapy. Based on the results of a single-center observational study involved patients treated in Department of Nephrology, Transplantation and Internal Diseases, Medical University of Silesia in Katowice, Poland [12].

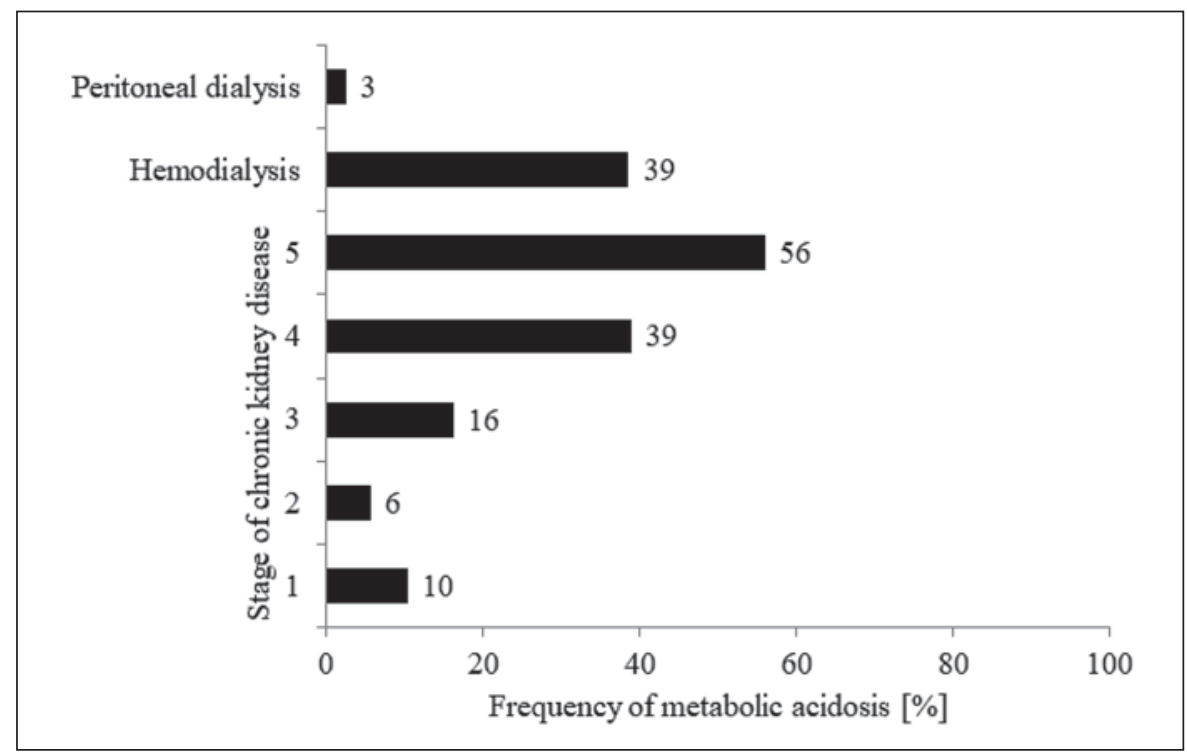

\section{Pathogenesis of Metabolic Acidosis in CKD}

The most important risk factor of metabolic acidosis in CKD is reduced glomerular filtration. The risk of metabolic acidosis is significantly increased in patients with CKD and glomerular filtration rate (GFR) $<40 \mathrm{~mL} /$ $\mathrm{min} / 1.73 \mathrm{~m}^{2}$. Metabolic acidosis usually occurs when the glomerular filtration is reduced to $20-30 \mathrm{~mL} / \mathrm{min} / 1.73$ $\mathrm{m}^{2}$ [20]. In some studies, it was found that metabolic acidosis is more common in patients with CKD and diabetes [9]. However, in the study of Kuczera et al. [12], no differences were found in the frequency of metabolic acidosis depending on the etiology of CKD (glomerulonephritis $-24 \%$, hypertensive renal disease $-23 \%$, diabetic kidney disease $-25 \%$, and interstitial kidney disease $-24 \%$ ). Other risk factors of metabolic acidosis in CKD include hyperkalemia and use of angiotensin-converting enzyme (ACE) inhibitors or angiotensin receptor blockers [9]. The analysis of the observational study by Raphael et al. [10] also showed that albuminuria $\geq 10 \mathrm{mg} / \mathrm{g}$, anemia, smoking, higher serum albumin, and greater waist circumference were associated with lower serum bicarbonate. On the other hand, it was shown that diuretics reduce the risk of metabolic acidosis in CKD [10].

The causes of metabolic acidosis in patients with CKD are insufficient production of bicarbonate in distal tubule cells in the process of ammoniagenesis (60\% of excreted acids), disturbed secretion of protons (as titratable acidity) in the proximal and distal tubules (40\% excreted acids), and impaired reabsorption of bicarbonate in the kidney tubule. The main source of nonvolatile acids in the body is the metabolism of sulfur-containing amino acids (approximately 90\%) such as cystine, cysteine, and methionine; and the other amino acids as lysine, arginine, and histidine; phospholipid metabolism (5\%); glucose metabolism (lactic acid) (2\%); and fatty acid metabolism (1\%) [9]. As mentioned above, metabolic acidosis usually occurs when eGFR is reduced to below $20-30 \mathrm{~mL} /$ $\min / 1.73 \mathrm{~m}^{2}$. In earlier stages of CKD, for nephron loss compensation, the production of ammonia, in individual still active nephrons, is increased to more than double. With the CKD progression, complete correction of the above-described abnormalities becomes not possible and a decrease in bicarbonate plasma or blood concentrations is observed. In most patients with CKD stages $1-5$, metabolic acidosis is characterized with the normal anion gap. In some patients with CKD stage 5 , the anion gap may be increased due to the accumulation of phosphates, sulfates, and other anions in plasma $[9,21]$. Metabolic acidosis can also occur in the early stages of CKD when kidney tubular dysfunction such as tubular acidosis or hyporeninemic hypoaldosteronism associated with long-term diabetes happens [22-24].

The concentration of bicarbonate ions in plasma in patients with CKD depends on the degree of kidney dysfunction (which is expressed by the eGFR), the intake of acidic foods (primarily consisted of animal proteins, which contain a large amount of methionine and cysteine), the intake of alkalizing foods (primarily vegetables and fruits) (Fig. 5), and the efficiency of metabolic acidosis compensation mechanisms (related to the gastrointestinal tract and bones) $[7,25,26]$. To compare different 


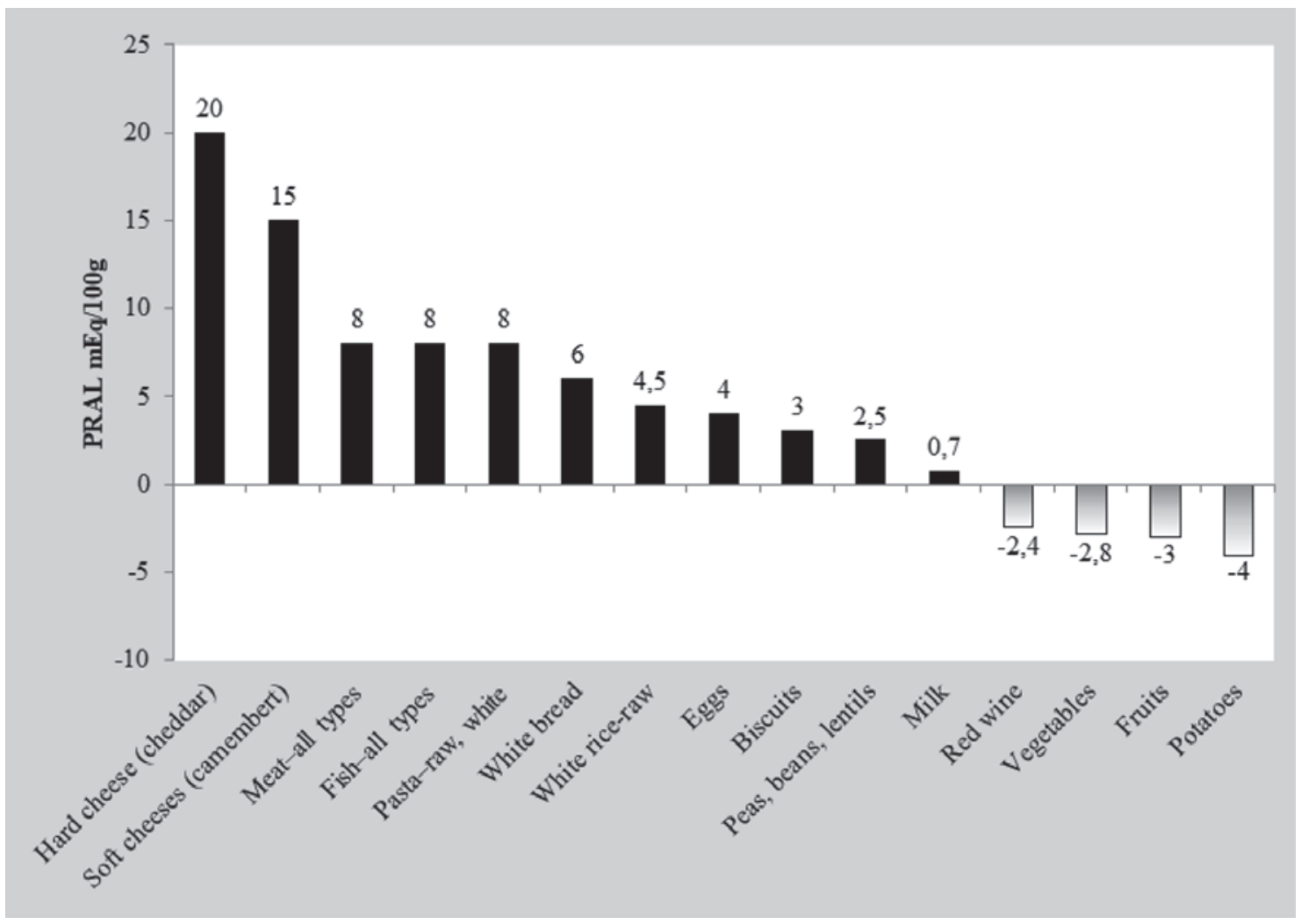

Fig. 5. Estimated acid load of the body depending on the type of food products. PRAL, potential renal acid load. Based on [27].

Table 2. Pathogenesis of metabolic acidosis in patients with CKD

\begin{tabular}{|c|c|}
\hline Pathogenesis of metabolic acidosis in CKD & References \\
\hline Reduction of the renal excretion of hydrogen ions & {$[20]$} \\
\hline Decrease in bicarbonate synthesis by the kidneys & {$[9]$} \\
\hline Reduction of tubular reabsorption of bicarbonate & {$[9]$} \\
\hline $\begin{array}{l}\text { Diet with low amount of alkalizing food (i.e., diet } \\
\text { with restriction of fresh fruits and vegetables for } \\
\text { prevention of hyperkalemia) }\end{array}$ & {$[7,25,26]$} \\
\hline
\end{tabular}

GFR, glomerular filtration rate.

food products, the potential renal acid load of food products was measured [27]. Net endogenous acid production (NEAP) is an indicator for assessing the amount of endogenous acids produced in the body. It is calculated according to the following formula: NEAP (mEq/day) = $-10.2+54.5 \times$ protein intake $(\mathrm{g} /$ day $) /$ potassium intake $(\mathrm{mmol} /$ day). Potassium intake $=$ kaliuria $(\mathrm{mmol} /$ day $)$. Protein intake is determined according to the Maroni for- mula: protein intake $(\mathrm{g} /$ day $)=6.35 \times$ (urea nitrogen in urine $[\mathrm{g} /$ day $]+0.031$ body weight) [28]. It has recently been shown that urinary excretion of citric acid might be an indicator of acid retention in the body. Goraya et al. [29] showed that in patients with CKD stages 1-2, in which acid retention occurs in the body, urinary excretion of citric acid is reduced. The pathogenesis of metabolic acidosis in patients with CKD is summarized in Table 2 .

\section{Consequences of Metabolic Acidosis in CKD}

As a result of metabolic acidosis in CKD, numerous metabolic processes are disturbed, leading to abnormal function of many systems and organs [30]. Chronic metabolic acidosis increases protein catabolism. It may participate in the pathogenesis of malnutrition-inflammation-atherosclerosis (MIA syndrome) [31, 32].

Metabolic acidosis contributes to the development of the inflammatory process in patients with CKD. It has been shown that in the acidic environment, the produc- 
Table 3. Consequences of metabolic acidosis

\begin{tabular}{|c|c|c|}
\hline Consequences of metabolic acidosis & Pathomechanism & References \\
\hline MIA syndrome & Increased protein catabolism (stimulation of proteolytic mechanisms) & {$[31,32]$} \\
\hline Inflammation & Increase in TNF- $\alpha$ secretion by macrophages & [33] \\
\hline $\begin{array}{l}\text { Impaired growth in children } \\
\text { Loss of muscle mass in adults }\end{array}$ & $\begin{array}{l}\text { Reduction of GH secretion and impairment of its peripheral activity } \\
\text { Abnormalities in the GH-IGF-1 axis }\end{array}$ & {$[34,35]$} \\
\hline $\begin{array}{l}\text { Hypercalcemia } \\
\text { Osteodystrophy } \\
\text { Osteoporosis }\end{array}$ & $\begin{array}{l}\text { Decreased calcium receptor sensitivity } \\
\text { Increased PTH secretion }\end{array}$ & {$[7,36]$} \\
\hline$\beta_{2}$-microglobulin myloidosis & Increased plasma concentration of $\beta_{2}$-microglobulin & {$[37]$} \\
\hline Insulin resistance & $\begin{array}{l}\text { Insulin sensitivity reduction } \\
\text { Increased liver gluconeogenesis } \\
\text { Decrease in insulin-dependent glucose uptake by muscles }\end{array}$ & {$[38-40]$} \\
\hline Hypothyroidism & Disorder of thyroxine conversion to triiodothyronine & {$[42]$} \\
\hline Anemia of chronic diseases & Increased hepcidin plasma concentration & {$[43-45]$} \\
\hline Dysfunction of cardiovascular system & $\begin{array}{l}\text { Increased stiffness of the vessel wall } \\
\text { Endothelial cell dysfunction }\end{array}$ & {$[46,47]$} \\
\hline Progression of CKD & $\begin{array}{l}\text { Stimulation of the renin-angiotensin system } \\
\text { Increased production of ROS } \\
\text { Increase in plasma ET-1 concentration } \\
\text { Local increase in ammonium ion concentration in the renal interstitium, } \\
\text { leading to stimulation of the complement system } \\
\text { Kidney interstitial fibrosis }\end{array}$ & {$[48-54]$} \\
\hline
\end{tabular}

MIA, malnutrition-inflammation-atherosclerosis; TNF- $\alpha$, tumor necrosis factor alpha; GH, growth hormone; IGF-1, insulin-like growth factor 1; PTH, parathyroid hormone; ROS, reactive oxygen species; ET-1, endothelin-1.

tion of tumor necrosis factor alpha by macrophages is increased [33].

In children with CKD, metabolic acidosis leads to impaired growth by inhibition of growth hormone $(\mathrm{GH})$ secretion and impairment of $\mathrm{GH}$ action in peripheral tissues. In metabolic acidosis, function of the entire $\mathrm{GH}$ insulin-like growth factor 1 (IGF-1) axis is disturbed. Decrease in free IGF-1 plasma concentration and increase in plasma IGF-1-binding protein concentration are also found. In adult CKD patients with metabolic acidosis, the above-mentioned endocrine disorders may participate in the pathogenesis of malnutrition $[34,35]$.

Metabolic acidosis adversely affects calcium and phosphate metabolism in patients with $\mathrm{CKD}$, reducing the sensitivity of the calcium receptor and by stimulating parathyroid hormone secretion [7]. It also contributes to the mobilization of bases from bones. Moreover metabolic acidosis stimulates osteoblasts to release prostaglandins and stimulates osteoclasts and reduces osteoblast activity [36]. It also intensifies osteodystrophy with high bone turnover and increases the risk of osteoporosis [36]. Metabolic acidosis may increase the plasma concentration of $\beta_{2}$-microglobulin and therefore contributes to the development of $\beta_{2}$-microglobulin amyloidosis [37].

In patients with CKD without diabetes, metabolic acidosis leads to insulin resistance, and alkaline treatment with sodium bicarbonate increases insulin sensitivity [38-40]. In patients with CKD and hypertriglyceridemia, sodium bicarbonate therapy causes a reduction in serum triglyceride concentrations [41]. In patients with CKD, metabolic acidosis impairs the peripheral conversion of thyroxine to triiodothyronine, which results in a decrease in serum triiodothyronine concentration [42].

In addition, the results of animal experiments indicate that metabolic acidosis in patients with CKD may increase the serum hepcidin concentration and thus participates in the pathogenesis of anemia of chronic diseases $[43,44]$. Metabolic acidosis has been shown to increase the need for erythropoiesis-stimulating agents in CKD patients treated with hemodialysis [45]. 
Fig. 6. Effect of metabolic acidosis on the progression of CKD. RAA, renin-angiotensin-aldosterone system; ROS, reactive oxygen species; ET-1, endothelin-1; C3, C5b-9, components of the complement system. Based on [51-54].

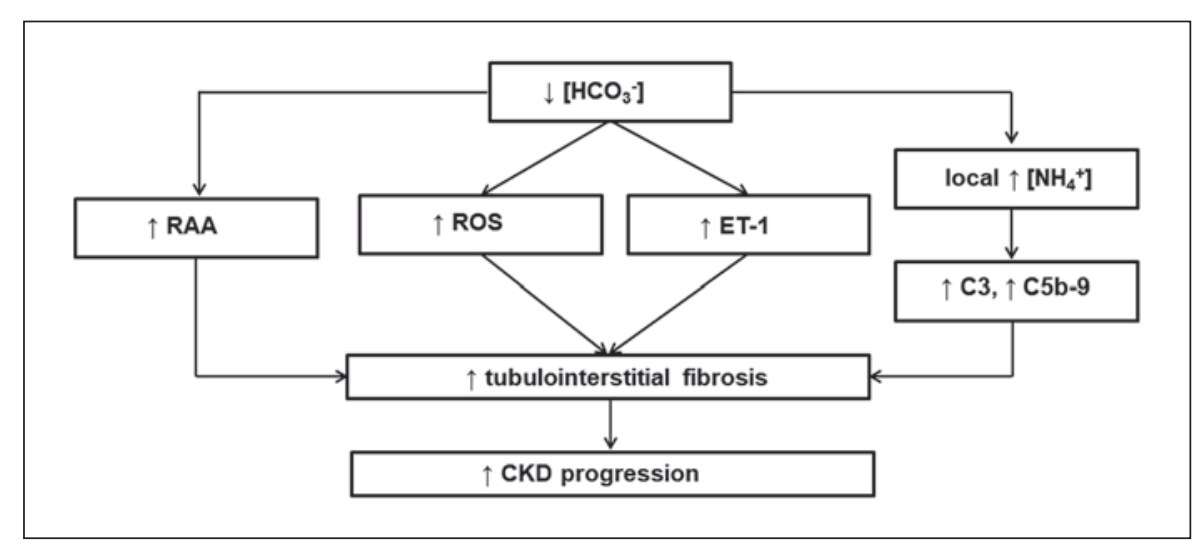

Metabolic acidosis in CKD adversely affects the cardiovascular system. Kim et al. [46] analyzed the effect of metabolic acidosis on arterial stiffness. The study included 1,659 patients with CKD. Among them, 210 were characterized by metabolic acidosis. It was shown that arterial stiffness, assessed on the basis of pulse wave velocity, was higher in patients with CKD and metabolic acidosis $(p<0.001)$ [46]. Kendrick et al. [47] in a prospective study of 20 patients with GFR of $15-44 \mathrm{~mL} / \mathrm{min} / 1.73 \mathrm{~m}^{2}$ and serum bicarbonate concentration of $16-21 \mathrm{mmol} / \mathrm{L}$ analyzed the effect of sodium bicarbonate treatment on vascular endothelial function. It has been shown that after 14 days of sodium bicarbonate treatment, the flow-mediated dilatation of the brachial artery is increased. The results of the study have shown that the treatment of metabolic acidosis with sodium bicarbonate significantly improves vascular endothelial function in patients with CKD [47].

In addition, as described in detail below, the metabolic acidosis accelerates the progression of CKD [48]. The above-described consequences of metabolic acidosis in CKD are presented in Table 3.

\section{Metabolic Acidosis and CKD Progression}

The results of numerous animal studies described below indicate that metabolic acidosis stimulates the progression of CKD. Wesson et al. [49] in a study on $\mathrm{Mu}$ nich-Wistar rats, which were given casein (animal protein with acidifying potential) or soybean protein (vegetable protein with alkalizing properties) for 12 weeks, evaluated kidney function. In the study, casein was shown to increase acid production, leading to a decrease in renal function. Metabolic acidosis due to casein intake has been shown to cause tubulointerstitial damage [49, 50]. In the study, it was also found that the administration of durosentan (endothelin-1 receptor antagonist) reduces the severity of interstitial kidney damage in MunichWistar rats with metabolic acidosis [49]. Another experimental study done by Tammaro et al. [51] evaluated the effect of metabolic acidosis on renal function in C57BL/6 mice. Metabolic acidosis was induced in these mice by administration of ammonium chloride $\left(\mathrm{NH}_{4} \mathrm{Cl}\right)$ in drinking water or by the use of an acidifying diet, that is, based on food with the addition of an aqueous solution of hydrogen chloride $(\mathrm{HCl})$. Kidney damage was assessed by GFR and by histological examination. It has been shown that glomerular hyperfiltration occurred within 1-3 days of the acidifying diet. After 1 week, GFR returned to baseline and then gradually decreased during observational period of 21 days. The decrease in GFR was associated with the development of renal fibrosis, which was demonstrated in histopathological analysis with the Masson trichrome staining. Indicators of kidney fibrosis such as a-smooth muscle actin and type 1 collagen increased after 1 day of acid load and remained higher than those observed at the beginning of the study and throughout the duration of the experiment, that is, for 21 days. The concentration of transforming growth factor beta and the activity of the intrarenal renin-angiotensin-aldosterone system were increased, even before the observed decrease in GFR [51].

It is believed that the loss of active nephrons causes a reduction in total ammoniagenesis in the kidneys. Ammoniagenesis in the remaining, still active, tubules is increased. This results in the ammonia transfer not only to the tubular lumen (which occurs physiologically - in these circumstances, $80 \%$ of ammonia synthesis) but also to the kidney interstitium (remaining $20 \%$ of ammonia synthesis). In studies on rats subjected to subtotal nephrectomy, it was found that such local ammonia excess in the renal interstitium stimulates factor $\mathrm{C} 3$ synthesis 
followed by an increase in activity of alternative complement pathway with the C5b-9 complex. Activation of the complement system as a result of a local increase in ammonia concentration stimulates the inflammatory process and leads finally to renal interstitial fibrosis (Fig. 6) [52].

Metabolic acidosis in male Sprague-Dawley rats (induced by $\mathrm{NH}_{4} \mathrm{Cl}$ administration) has been shown to lead to increased urinary excretion of 8-isoprostane and increased concentrations of oxidative stress indicators (8-isoprostane, BP-1, and 4-(aminoethylene)-cyclopentane-1,3-dione) in the renal cortex, which results in renal interstitial fibrosis (Fig. 6) [53]. In addition, metabolic acidosis in male Sprague-Dawley rats (caused by administration of $\mathrm{NH}_{4} \mathrm{Cl}$ ) increases the expression of angiotensinogen, $\mathrm{ACE}$ and angiotensin $\mathrm{II}_{\mathrm{AT}}$ receptor, which also increases renal interstitial fibrosis (Fig. 6) [54].

\section{Metabolic Acidosis and Prognosis in CKD}

A prospective observational CRIC study evaluated serum bicarbonate concentration as $\mathrm{CKD}$ progression risk factor (i.e., eGFR reduction by $>50 \%$ or kidney replacement therapy initiation). It has been shown that in patients with serum bicarbonate concentration $<22 \mathrm{mmol} / \mathrm{L}$, the progression of CKD is about 3 times more pronounced than in patients with serum bicarbonate concentration $>26 \mathrm{mmol} / \mathrm{L}$ [55]. In the observational 4C study, Harambat et al. [13] showed that in children and adolescents with $\mathrm{CKD}$ and serum bicarbonate concentration $<18$ $\mathrm{mmol} / \mathrm{L}$, the risk of eGFR reduction by $>50 \%$ or achieving eGFR below $10 \mathrm{~mL} / \mathrm{min} / 1.73 \mathrm{~m}^{2}$ or initiating renal replacement therapy was 2.4 times higher compared to patients with serum bicarbonate concentrations $>18$ $\mathrm{mmol} / \mathrm{L}$. Gojowy et al. [56] in a 3-year prospective observational study assessed the effect of blood bicarbonate concentration in kidney transplant patients on the risk of death or dialysis initiation. In patients with metabolic acidosis, the risk of death or the initiation of renal replacement therapy was significantly several times higher than in patients without metabolic acidosis $(\mathrm{RR}=4.11$ and $\mathrm{RR}=3.58$, respectively). In addition, in patients after kidney transplantation with metabolic acidosis, the concentration of bicarbonate in the blood at the beginning of the observation showed a positive correlation with the change in eGFR value during 3 years of observation [56].

In a multicenter, retrospective observational study lasting 5.2 years, done by Park et al. [57], in 2,318 patients 3 months after kidney transplantation, the influence of metabolic acidosis on the risk of kidney transplant loss was assessed. Serum bicarbonate concentration below 22 $\mathrm{mmol} / \mathrm{L}$ in renal transplant patients has been shown to be associated with an increased risk of renal transplant loss $(\mathrm{RR}=1.74)$. Not only metabolic acidosis per se leads to an increase in CKD progression, but also, as demonstrated by Scialla et al. [58] and Toba et al. [59], excessive production of endogenous acids in the body (assessed using NEAP) related to low-vegetable diet.

Raphael et al. [60] in a retrospective observational study (part of the National Health and Nutrition Examination Survey III, NHANES III) involving 1,267 patients with CKD and a follow-up of 8.6 years showed that low plasma bicarbonate concentration $(<22 \mathrm{mmol} / \mathrm{L})$ was associated with a 2.6-fold higher risk of death. Navaneethan et al. [61] in a 4-year retrospective observational study involving 41,749 patients with CKD at stages $3-4$ showed that metabolic acidosis worsens the prognosis in patients with eGFR $30-60 \mathrm{~mL} / \mathrm{min} / 1.73 \mathrm{~m}^{2}$. Kovesdy et al. [62] observed in a retrospective study of 1,240 patients with CKD stages 2-5 (57\% with CKD stage 3 ) that serum bicarbonate concentration showed a significant relationship, U-shaped, with mortality. The highest mortality was observed in patients with plasma bicarbonate concentration $<22 \mathrm{mmol} / \mathrm{L}$ [62]. Taking into account the results of the above observational studies, it can be concluded that metabolic acidosis adversely affects the prognosis in patients with CKD.

\section{Treatment of Metabolic Acidosis and CKD Progression}

The first data on the beneficial effects of alkalizing treatment on CKD progression were provided by a study published by Lyon et al. [63] in The Lancet in 1931. Currently, sodium bicarbonate is mainly used in the pharmacological treatment of metabolic acidosis in patients with CKD (Table 2) [9].

de Brito-Ashurst et al. [64] assessed the effect of sodium bicarbonate treatment on CKD progression in a 2 -year intervention study involving 134 adult patients with CKD. The study included patients with eGFR 15-30 $\mathrm{mL} / \mathrm{min} / 1.73 \mathrm{~m}^{2}$ and serum bicarbonate concentration $16-20 \mathrm{mmol} / \mathrm{L}$. The goal of the treatment was to achieve serum bicarbonate concentration higher than or equal to $23 \mathrm{mmol} / \mathrm{L}$. The mean dose of sodium bicarbonate used in this study was about $1.8 \mathrm{~g}$. In this study, the CKD progression was assessed using eGFR. Patients treated with sodium bicarbonate showed less severe reduction of 
eGFR compared to the control group (1.9 vs. $5.9 \mathrm{~mL} /$ $\mathrm{min} / 1.73 \mathrm{~m}^{2} /$ year). In the study, the study endpoint was initiation of dialysis therapy. It was shown that in the group treated with sodium bicarbonate, fewer patients needed dialysis (4 vs. 22) [64].

Alva et al. [65] studied the effect of alkalizing treatment with sodium bicarbonate on eGFR, plasma albumin concentration, and muscle mass. The study included 67 patients with CKD who received sodium bicarbonate or placebo. The duration of therapy was 9 months. It was shown that eGFR in the patients treated with sodium bicarbonate did not decrease compared to the values at the beginning of the study, while in the patients receiving placebo, it decreased by $1.3 \mathrm{~mL} / \mathrm{min} / 1.73 \mathrm{~m}^{2}$. Moreover, patients treated with sodium bicarbonate at the end of the study are characterized by a higher plasma albumin concentration and higher muscle mass compared to patients receiving placebo [65].

The prospective, randomized UBI study compared the effect of sodium bicarbonate versus placebo in 740 patients with CKD on serum creatinine, likelihood of initiating dialysis, and mortality. Patients with eGFR $<60 \mathrm{~mL} /$ $\mathrm{min} / 1.73 \mathrm{~m}^{2}$ and serum bicarbonate concentration $18-24$ $\mathrm{mmol} / \mathrm{L}$ were included in the study. The goal of the treatment was to achieve serum bicarbonate concentration in the range of $24-28 \mathrm{mmol} / \mathrm{L}$. The dose of sodium bicarbonate used to achieve this goal of therapy was about $6 \mathrm{~g} /$ day. The observation period was 30 months. In patients receiving sodium bicarbonate, the concentration of serum bicarbonate after 36 months was $26 \mathrm{mmol} / \mathrm{L} \mathrm{(22-30}$ $\mathrm{mmol} / \mathrm{L}$ ), while in patients receiving placebo, $22 \mathrm{mmol} / \mathrm{L}$ (17-26 mmol/L). In patients undergoing sodium bicarbonate treatment, the reduction in eGFR was less than in those treated with placebo ( 1.4 vs. $3.4 \mathrm{~mL} / \mathrm{min} / 1.73 \mathrm{~m}^{2}$ ). Seven percent of patients using sodium bicarbonate initiated dialysis, while $12 \%$ of patients receiving placebo $(p=$ $0.02)$. Moreover, mortality in patients receiving sodium bicarbonate was lower than in patients receiving placebo ( 3 vs. $7 \% ; p=0.005$ ). There was no significant effect of sodium bicarbonate therapy on blood pressure, total body weight, or the number of hospitalization [6]. In the above study, the initial daily dose of sodium bicarbonate was calculated to replace half of the bicarbonate deficit in the body by the formula: bicarbonate (in $\mathrm{mmol})=(24-$ serum bicarbonate concentration in $\mathrm{mmol} / \mathrm{L}) \times($ total body weight $[\mathrm{kg}] \times 0.5)$. For example, in a patient with a body weight of $75 \mathrm{~kg}$ and a serum bicarbonate concentration of $16 \mathrm{mmol} / \mathrm{L}$, the initial daily dose of sodium bicarbonate should be $3.2 \mathrm{~g}$, while in a patient with a body weight of $75 \mathrm{~kg}$ and a serum bicarbonate concentration of
$20 \mathrm{mmol} / \mathrm{L}$, the initial daily dose of sodium bicarbonate should be $1.6 \mathrm{~g}$. Then, the dose of sodium bicarbonate was modified until the serum bicarbonate concentration reached $24 \mathrm{mmol} / \mathrm{L}$ [6].

Sodium bicarbonate should be given 2 or 3 times a day. It is generally thought that the initial daily dose of sodium bicarbonate is $1-2 \mathrm{~g}$. The use of sodium bicarbonate in high doses (i.e., above $6 \mathrm{~g} /$ day), especially during large meals, may (although extremely rarely) lead to clinically significant increase in stomach volume (by releasing carbon dioxide), which can result in the rapture of the stomach wall. To prevent this complication, it is recommended to use sodium bicarbonate between meals and coated (i.e., enteric) preparations are preferred. Sodium bicarbonate tablets and capsules are usually better tolerated, and the dosing used may be more accurate than in the case of treatment with sodium bicarbonate powder [7,9]. When sodium bicarbonate powder is used, it should be remembered that $1 \mathrm{~g}$ of sodium bicarbonate powder is $1 / 5$ teaspoon.

Sodium citrate is another alkalizing drug used in the treatment of metabolic acidosis in patients with CKD [8]. In a study of Phisitkul et al. [66], in 59 patients with hypertensive nephropathy and eGFR $20-60 \mathrm{~mL} / \mathrm{min} / 1.73$ $\mathrm{m}^{2}$ and metabolic acidosis, sodium citrate versus placebo was administered and eGFR was evaluated. The duration of the study was 30 months, including 24 months of oral sodium citrate treatment. In the study, it was found that treatment with sodium citrate in patients with hypertensive nephropathy reduced the eGFR decline from 3.8 to $1.9 \mathrm{~mL} / \mathrm{min} / 1.73 \mathrm{~m}^{2} /$ year [66]. It should be mentioned that the administration of sodium citrate does not increase the serum bicarbonate concentration in patients with liver insufficiency because the conversion of citrates to bicarbonates occurs mainly in this organ [7].

The subject of controversy is the issue of target values of plasma or blood bicarbonate concentration in patients with CKD. The results of a recent UBI study indicate that the target value for plasma or blood bicarbonate should be $24-28 \mathrm{mmol} / \mathrm{L}$, which is higher than target $22 \mathrm{mmol} / \mathrm{L}$ usually used in the past $[6,7]$.

The expanded concept of metabolic acidosis assumes that some patients with CKD and normal plasma bicarbonate concentration have latent acid retention (so-called subclinical metabolic acidosis). Rats with $2 / 3$ subtotal nephrectomy develop mild CKD. In these rats, normal plasma bicarbonate concentration was found. However, microdialysis study documented acid retention in kidney interstitium of $2 / 3$ subtotal nephrectomized rats. Moreover, in these rats, alkalizing treatment corrects acid re- 
tention and preserves kidney function [67]. The occurrence of subclinical metabolic acidosis might be associated with the progression of CKD in humans, as well [68, 69]. Mahajan et al. [70] studied 120 hypertensive patients with CKD stage 2 (mean eGFR $75 \mathrm{~mL} / \mathrm{min} / 1.73 \mathrm{~m}^{2}$ ) with normal bicarbonate serum concentration (mean bicarbonate serum concentration $26 \mathrm{mmol} / \mathrm{L}$ ). Patients were treated with sodium bicarbonate or equimolar amount of sodium chloride or placebo during 5 years. eGFR decline during 5 years of study in patients treated with sodium bicarbonate was significantly lower than that in those treated with sodium chloride and placebo (8.0 vs. $10.4 \mathrm{vs.}$ $11.6 \mathrm{~mL} / \mathrm{min} / 1.73 \mathrm{~m}^{2}$, respectively, $p=0.020$ ) [70].

However, the diagnosis methods of subclinical metabolic acidosis have not yet been established. Reduced excretion of citrate and ammonium ions in the urine seems to be indicators of acid retention and might be used in future in the diagnosis of subclinical metabolic acidosis in CKD patients. This issue requires undoubtedly further studies $[68,69]$.

\section{Safety of Alkalizing Drugs}

The first safety issue of alkalizing drugs to be discussed is the potential hypertensinogenic properties of sodium contained sodium bicarbonate. Studies in rats with deoxycorticosterone-induced hypertension (DOCA-saltsensitive rats) and in rats with spontaneous hypertension susceptible to stroke (spontaneously hypertensive stroke prone rats) have shown that sodium bicarbonate does not lead to an increase in blood pressure [71-73].

Luft et al. [74] in a clinical study of 10 patients with mild hypertension and 10 subjects with normal blood pressure analyzed the effect of sodium chloride and sodium bicarbonate on blood pressure. Subjects during low-sodium diet were given additionally $78 \mathrm{mmol}$ of sodium bicarbonate or equimolar amounts of sodium chloride daily for 7 days. It was found that in healthy subjects and patients with hypertension, sodium bicarbonate, unlike sodium chloride, did not exhibit hypertensinogenic properties. What is more, sodium bicarbonate was shown to reduce systolic blood pressure by $5 \mathrm{~mm} \mathrm{Hg}$ in hypertensive patients [74]. Husted et al. [75] conducted a study in patients with advanced CKD. In this study, 10 patients with CKD with eGFR of $3-17 \mathrm{~mL} / \mathrm{min} / 1.73 \mathrm{~m}^{2}$ were added to the diet with $207 \mathrm{mmol}$ sodium chloride versus 201 mmol sodium bicarbonate daily for 4 days. It was found that similar to subjects with normal kidney function, in patients with advanced CKD, sodium bicarbonate, unlike sodium chloride, did not exhibit hypertensinogenic properties. The stable sodium balance during administration of sodium bicarbonate was due to the preserved ability of the kidneys to excrete sodium. In contrast to sodium bicarbonate, administration of sodium chloride led to a positive sodium balance [75]. The results of long-term clinical studies conducted in patients with CKD also do not indicate that sodium bicarbonate is characterized by hypertensinogenic properties. At the beginning of the study by de Brito Ashurst et al. [64], hypertension occurred in $48 \%$ of patients, but after 24 months, it was found in $61 \%$ of them $(p=0.17)$. In the UBI study, there was no increase in blood pressure or the need for intensification of antihypertensive treatment in patients treated with sodium bicarbonate [6]. When analyzing the neutral effect of sodium bicarbonate on blood pressure, it should be emphasized that the dose of sodium supplied with sodium bicarbonate is not too high. In the study of de BritoAshurst et al. [64], the daily dose of sodium bicarbonate was $1.82 \mathrm{~g}$, which contains $499 \mathrm{mg}$ of sodium. Considering that the amount of sodium in the diet of European inhabitants is $3,600-4,800 \mathrm{mg} /$ day, one may estimate that sodium intake with sodium bicarbonate constitutes 10$14 \%$ of sodium usually consumed in the diet [64].

The second safety issue of alkalizing treatment that needs to be discussed is the concern of causing metabolic alkalosis in patients with CKD. Treatment of metabolic acidosis with sodium bicarbonate at the most commonly used doses (2-3 g/day) extremely rarely might lead to metabolic alkalosis. However, temporary discontinuation of sodium bicarbonate should be considered in clinical settings that may promote the development of metabolic alkalosis (e.g., vomiting and hypokalemia). To prevent excessive alkalization during treatment with sodium bicarbonate, the concentration of bicarbonate in plasma or blood should be monitored [7].

In the observational CRIC study, a relationship between serum bicarbonate concentration and the incidence of congestive heart failure was found. It was shown that for each increase of $1 \mathrm{mmol} / \mathrm{L}$ in serum bicarbonate concentration above $24 \mathrm{mmol} / \mathrm{L}$, the risk of congestive heart failure is increased by $14 \%$. Moreover patients with serum bicarbonate concentrations above $26 \mathrm{mmol} / \mathrm{L}$ were characterized by an increased risk of heart failure and mortality $[55,76]$. In an observational study by $\mathrm{Na}-$ vaneethan et al. [61] congestive heart failure and chronic obstructive pulmonary disease (COPD) were more common in patients with serum bicarbonate $>32 \mathrm{mmol} / \mathrm{L}$ compared to patients with serum bicarbonate concentration of $23-32 \mathrm{mmol} / \mathrm{L}$ ( 22 vs. $9 \%$ and 20 vs. $9 \%$, respec- 
tively). The increase in mortality in patients with serum bicarbonate concentrations $>26$ or $>32 \mathrm{mmol} / \mathrm{L}$, respectively, found in the above observational studies might be only the result from the higher incidence of congestive heart failure and COPD in these patients. Both these conditions adversely affect the prognosis in CKD patients. The increase in serum bicarbonate concentrations in these patients might be a result of potassium loss due to the use of diuretics (in patients with congestive heart failure) or increased $\mathrm{pCO}_{2}$ (in patients with COPD) [7].

\section{Use of a Diet Containing a High Content of Vegetables and Fruits as an Alternative to Alkalizing Pharmacotherapy in Patients with CKD and Metabolic Acidosis}

The human diet has changed significantly over the centuries. The study by Sebastian et al. [77] conducted an analysis of 159 different diets from the period before the introduction of agriculture (about 10,000 years ago) showing that NEAP at that time was $-88 \mathrm{mEq} /$ day. Thus, the results of this study suggest that the Paleolithic diet was alkalizing. Currently, NEAP is $+48 \mathrm{mEq} /$ day. This indicates that the modern diet is acidifying [77]. In the study of Scialla and Anderson [25], 462 patients with CKD and hypertensive nephropathy (GFR 20-65 mL/ $\min / 1.73 \mathrm{~m}^{2}$ ) participating in the AASK study (African American Study of Kidney Disease and Hypertension) were divided according to NEAP. Higher NEAP was associated with lower serum bicarbonate concentrations [25]. Therefore, in humans, the acidifying diet leads to metabolic acidosis [25].

Rebholz et al. [78] completed the analysis of data of the ARIC study (Atherosclerosis Risk in Communities), in which in 15,055 subjects, the effect of dietary acid load (estimated as potential renal acid load) on the risk of CKD was studied. After 21 years of follow-up, in $16 \%$ of the studied subjects, CKD was diagnosed. A higher dietary acid load was associated with higher risk of incident CKD (HR for quartile 4 vs. 1:1.13, 95\% CI 1.01-1.28, $p$ for trend $=0.02$ ). Each interquartile range increase of dietary acid load was associated with $6 \%$ higher risk of incident CKD (HR 1.06, 95\% CI 1.00-1.11, $p=0.04$ ). The authors of the study suggest that reducing the dietary acid intake might reduce CKD risk [78].

The study of Goraya et al. [79] evaluated the effect of observation versus sodium bicarbonate versus alkalizing diet, that is, diet rich in vegetables and fruits $(\mathrm{F}+\mathrm{V}$ diet $)$ prescribed by a dietician and delivered to the home free of charge for the whole family, on the albuminuria/creatinuria ratio in CKD patients. The study included $71 \mathrm{pa}-$ tients with CKD stage $1\left(\mathrm{eGFR}>90 \mathrm{~mL} / \mathrm{min} / 1.73 \mathrm{~m}^{2}\right)$ without diabetes with hypertensive nephropathy and albuminuria. During 1-year observational period, albuminuria/creatinuria ratio in the observation group increased. The use of both sodium bicarbonate and the F + $\mathrm{V}$ diet prevented such an increase in the albumin/creatinine ratio [79]. In another study, in 108 patients with plasma $\mathrm{CO}_{2}$ concentrations $22-24 \mathrm{mmol} / \mathrm{L}$ before the study and CKD stage 3 (eGFR $30-59 \mathrm{~mL} / \mathrm{min} / 1.73 \mathrm{~m}^{2}$ ) with hypertensive nephropathy and without diabetes, the effect of observation versus sodium bicarbonate versus $\mathrm{F}+\mathrm{V}$ diet administration on metabolic acidosis was assessed. Patients enrolled into the study were selected according to the tendency to hyperkalemia. Patients participating in this study are characterized by no tendency to hyperkalemia. In these patients, despite they were treated with ACE inhibitors, plasma potassium concentration always was $<4.6 \mathrm{mmol} / \mathrm{L}$. The observation period was 3 years. A similar metabolic acidosis correction and urinary acid excretion were demonstrated in patients treated with sodium bicarbonate versus the $\mathrm{F}+\mathrm{V}$ diet. In addition, a similar decrease in CKD progression and a similar decrease in albuminuria were found in patients treated with sodium bicarbonate or an $\mathrm{F}+\mathrm{V}$ diet, respectively [80]. In another 1-year clinical study by Goraya et al. [81], the impact of the above interventions on eGFR, albuminuria, systolic blood pressure, and plasma potassium concentrations was evaluated in patients with hypertensive nephropathy and metabolic acidosis. The study involved 76 patients with hypertensive nephropathy (eGFR $15-29 \mathrm{~mL} / \mathrm{min} / 1.73 \mathrm{~m}^{2}$ ) without diabetes and with metabolic acidosis. Similarly, as in former study, patients in the study are characterized by no tendency to hyperkalemia. A similar metabolic acidosis correction was demonstrated in patients treated with sodium bicarbonate as well as the F + V diet. Similar eGFR and similar reduction in albuminuria were also demonstrated in the group of patients treated with sodium bicarbonate versus the F $+\mathrm{V}$ diet. Systolic blood pressure in patients treated with sodium bicarbonate remained unchanged, while in patients treated with $\mathrm{F}+\mathrm{V}$ diet, it was reduced by $5 \mathrm{~mm}$ $\mathrm{Hg}(p<0.01)$. At the beginning of the study, patients on the $\mathrm{F}+\mathrm{V}$ diet had a plasma potassium concentration of $4.1 \mathrm{mmol} / \mathrm{L}$, and it did not increase after 1 year of followup [81].

It should be noted that the above-cited clinical studies did not fully assess the risk of hyperkalemia during a diet rich in fresh vegetables and fruits in patients with im- 


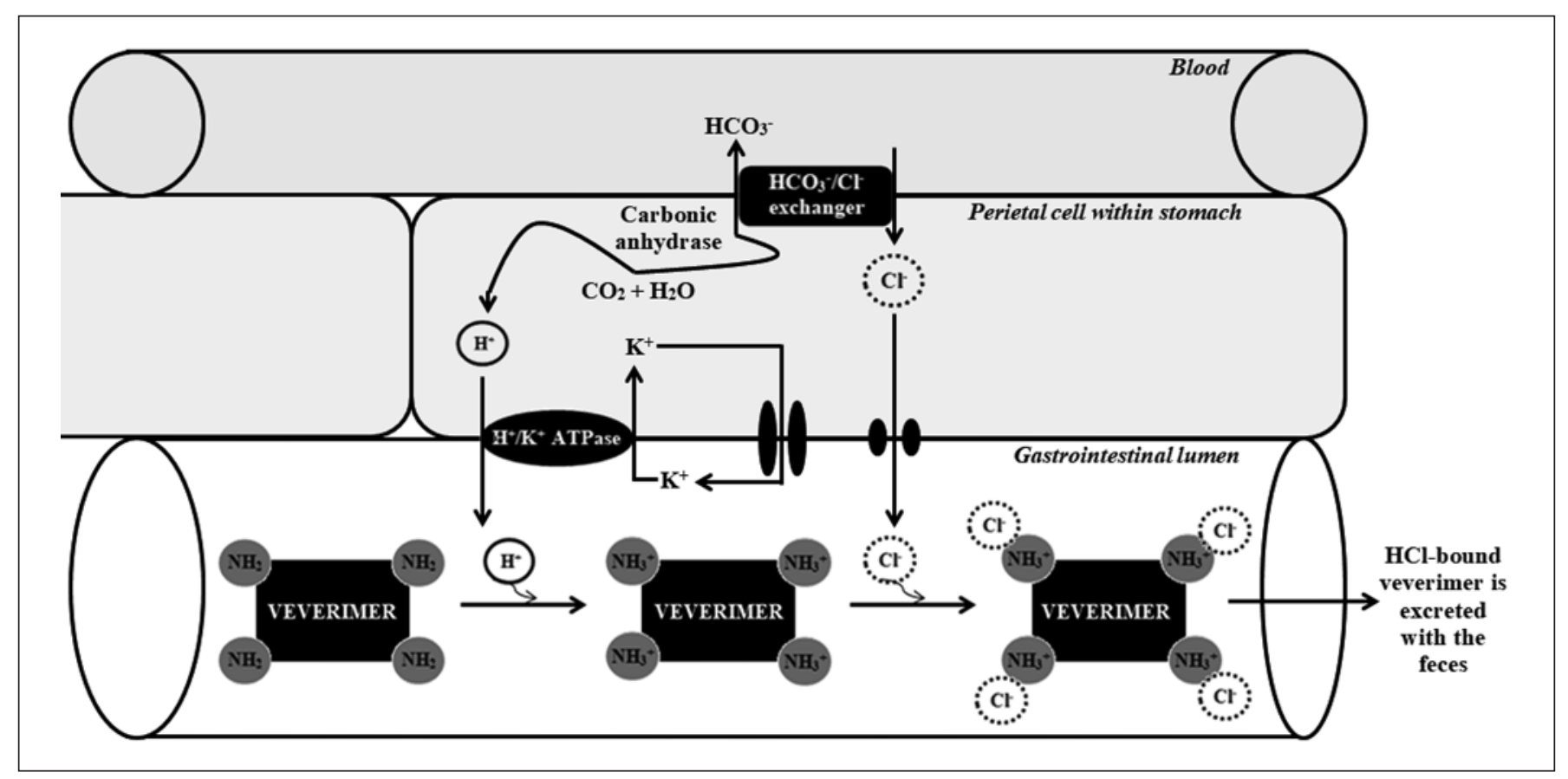

Fig. 7. The mechanism of veverimer action.

paired kidney function, because only patients with a low risk of hyperkalemia, that is, patients without diabetes and patients with plasma potassium concentrations always $<4.6 \mathrm{mmol} / \mathrm{L}$, were included. Kaliemia was also closely monitored in these patients during the clinical trial. So far, no studies have been conducted on the safety of diet with an increased content of vegetables and fruits in patients with CKD in the conditions of daily medical practice, that is, outside the clinical trial.

\section{New Drug Used to Treat Metabolic Acidosis in CKD}

Veverimer (TRC101) is a first-in-class proton-binding nonabsorbable free-amine polymer. Within the parietal cell in the stomach, water plus carbon dioxide is converted under the influence of carbonic anhydrase into hydrogen cation and carbohydrate anion. Hydrogen cation is secreted from the gastric parietal cell into the gastrointestinal lumen in exchange for potassium cation through the action of the $\mathrm{H}^{+} / \mathrm{K}^{+}$ATPase. Veverimer binds hydrogen cation with high capacity in the gastrointestinal lumen, and every bound hydrogen cation results in a carbohydrate anion entering the blood via basolateral exchange with serum chloride anion, which leads to an increase in serum bicarbonate. Afterward, in the gastrointestinal lu- men, veverimer binds chloride anion with high selectivity. Finally, hydrogen- and chloride-bound veverimer is excreted with the feces (Fig. 7) [82]. This mechanism of acid removal is similar to the physiological response to prolonged vomiting or to nasogastric suction.

Bushinsky et al. [83] assessed the effectiveness of veverimer in metabolic acidosis treatment in 135 patients with eGFR $20-60 \mathrm{~mL} / \mathrm{min} / 1.73 \mathrm{~m}^{2}$ and serum bicarbonate concentration $12-20 \mathrm{mmol} / \mathrm{L}$. The patients were given $1.5,3,4.5$, or $6 \mathrm{~g}$ of veverimer per day for 2 weeks. There was an increase in serum bicarbonate of 3.2-3.9 mmol/L compared with placebo. Serum bicarbonate concentration was normalized in 35\% of these patients [83].

Wesson et al. [84] in a randomized, double-blind, multicenter study with placebo evaluated the efficacy and safety of veverimer in patients with CKD. The study included 217 patients with CKD and eGFR $20-40 \mathrm{~mL} /$ $\min / 1.73 \mathrm{~m}^{2}$ and serum bicarbonate concentrations $16-20 \mathrm{mmol} / \mathrm{L}$. Patients were given veverimer at a dose of $6 \mathrm{~g} /$ day or placebo for 12 weeks. The administration of veverimer led to an increase in serum bicarbonate concentration of $4.5 \mathrm{mmol} / \mathrm{L}$. Normalization of the serum bicarbonate concentration was achieved in $50 \%$ of patients with CKD. The most common adverse reactions following the use of veverimer were gastrointesti- 
nal disorders (17 vs. $9 \%$ ), such as diarrhea (9 vs. $3 \%$ ) [84].

Wesson et al. [85] in a multicenter, randomized, double-blind, placebo-controlled study, which was a continuation of the above-described study lasting 12 weeks assessed the long-term (40 more weeks) safety and efficacy of veverimer therapy. In this extension study, participants continued with the same treatment assignment as in the parent study. It was shown that $3 \%$ of veverimer compared with $10 \%$ of placebo patients discontinued treatment prematurely, while no veverimer patients discontinued treatment due to adverse events. It was found that in $63 \%$ of the veverimer patients versus $38 \%$ of the placebo patients, $\mathrm{a} \geq 4 \mathrm{mmol} / \mathrm{L}$ increase in serum bicarbonate concentration or normalization of serum bicarbonate concentration was observed $(p=0.0015)$. Patients who received veverimer showed a significant $(p<0.0001)$ improvement in physical fitness (assessed according to the Kidney Disease and Quality of Life-Physical Function Domain) [85]. In the study, the authors showed a statistically significant improvement in prognosis (i.e., less frequent achievement of a composite endpoint: number of deaths, the need for kidney replacement therapy, or a reduction in eGFR by $>50 \%$ ) in patients treated with veverimer compared to placebo (4 vs. $12 \%$, respectively) [85]. The results of the above-described studies open up new perspectives for the treatment of metabolic acidosis in CKD.

Despite the promising data showing that veverimer is well tolerated and effective in the treatment of metabolic acidosis in patients with CKD, it is not known how this drug may affect the gut microflora and electrolyte balance. In addition, the most effective and safe dose of this drug should be determined [86]. The randomized, double-blind, placebo-controlled study "Evaluation of Effect of TRC101 on Progression of Chronic Kidney Disease in Subjects with Metabolic Acidosis (VALOR-CKD)" is currently under recruitment, evaluating the effect of veverimer on CKD progression in patients with metabolic acidosis (NCT03710291). The results of the study may provide further data concerning veverimer therapy. The study is scheduled for completion in December 2024.

\section{Conclusions}

1. Metabolic acidosis occurs in approximately $20 \%$ of patients with CKD.

2. The frequency of metabolic acidosis in patients with CKD increases with a decrease in GFR.

3. Metabolic acidosis accelerates the progression of CKD.

4. Treatment of metabolic acidosis with sodium bicarbonate reduces the CKD progression and is well tolerated.

5. The importance of sodium citrate, veverimer, and a diet rich in fruits and vegetables in the treatment of metabolic acidosis in patients with CKD requires further clinical studies.

6. Veverimer is a promising new drug in the treatment of metabolic acidosis.

\section{Conflict of Interest Statement}

M.A. received lecture fees from SANUM. S.S. declares that there is no conflict of interest regarding the publication of this article.

\section{Funding Sources}

The authors have no funding sources to report.

\section{Author Contributions}

M.A.: conceived the project, conducted literature search, wrote the paper, supervised, and coordinated all the work. S.S.: conducted literature search, wrote the paper, and drew figures and tables. All authors read and approved the final manuscript.

\section{References}

1 Hamm LL, Nakhoul N, Hering-Smith KS. Acid-base homeostasis. Clin J Am Soc Nephrol. 2015;10(12):2232-42.

2 Koeppen BM. The kidney and acid-base regulation. Adv Physiol Educ. 2009;33:275-81.

3 Weiner D, Mitch W, Sands J. Urea and ammonia metabolism and the control of renal nitrogen excretion. Clin J Am Soc Nephrol. 2015; 10:1444-58.

4 Elkinton J, Huth E, Webster G, McCance R. The renal excretion of hydrogen ion in renal tubular acidosis. I. Quantitative assessment of the response to ammonium chloride as an acid load. Am J Med. 1960;29:554-75.

5 Improving Global Outcomes (KDIGO). Kidney Int Suppl. 2013;3:1-150.

6 Di Iorio BR, Bellasi A, Raphael KL, Santoro D, Aucella F, Garofano L, et al. Treatment of metabolic acidosis with sodium bicarbonate delays progression of chronic kidney disease: the UBI Study. J Nephrol. 2019;32(6):9891001.
7 Adamczak M, Masajtis-Zagajewska A, Mazanowska O, Madziarska K, Stompór T, Więcek A. Diagnosis and treatment of metabolic acidosis in patients with chronic kidney disease: position statement of the working group of the Polish Society of Nephrology. Kidney Blood Press Res. 2018;43(3): 959-69.

8 Kraut JA, Kurtz I. Metabolic acidosis of CKD: diagnosis, clinical characteristics, and treatment. Am J Kidney Dis. 2005;45:978-93. 
9 Raphael KL. Metabolic acidosis in CKD: core curriculum 2019. Am J Kidney Dis. 2019;74: 263-75.

10 Raphael KL, Zhang Y, Ying J, Greene T. Prevalence of and risk factors for reduced serum bicarbonate in chronic kidney disease. Nephrology. 2014;19:648-54.

11 Skiba K, Gojowy D, Szotowska M, Bartmańska M, Kolonko A, Cierpka L, et al. Metabolic acidosis in kidney transplant recipients. Pol Arch Intern Med. 2018;128:587-93.

12 Kuczera P, Ciaston-Mogilska D, Oslizlo B, Hycki A, Wiecek A, Adamczak M. The prevalence of metabolic acidosis in patients with different stages of chronic kidney disease: single-centre study. Kidney Blood Press Res. 2020 Oct 16;45(6):863-72. Epub ahead of print.

13 Harambat J, Kunzmann K, Azukaitis K, Bayazit AK, Canpolat N, Doyon A, et al. Metabolic acidosis is common and associates with disease progression in children with chronic kidney disease. Kidney Int. 2017;92:1507-14.

14 Goutham KTC, Harichandrakumar KT, Dhanin P, Priyamvada PS, Haridasan S, Parameswaran S. Persistent metabolic acidosis on regular hemodialysis or peritoneal dialysis. Indian J Nephrol. 2019 Mar-Apr;29(2): 84-9.

15 Chang T, Oh H, Kang E, Yoo TH, Shin SK, Kang SW, et al. A low serum bicarbonate concentration as a risk factor for mortality in peritoneal dialysis patients. PLoS One. 2013; 8:e82912.

16 Szeto C, Kwan B, Chow K, Chung S, Yu V, Cheng PM, et al. Predictors of residual renal function decline in patients undergoing continuous ambulatory peritoneal dialysis. Perit Dial Int. 2015;35:180-8.

17 Liu X, Dai C. Advances in understanding and management of residual renal function in patients with chronic kidney disease. Kidney Dis. 2017;2(4):187-96

18 Belmar Vega L, Galabia ER, Bala de Silva J, Bentanachs González M, Fernández Fresnedo G, Piñera Haces C, et al. Epidemiology of hyperkalemia in chronic kidney disease. Nefrologia. 2019;39:277-86.

19 Harris AN, Grimm PR, Lee HW, Delpire E, Fang L, Verlander JW, et al. Mechanism of hyperkalemia-induced metabolic acidosis. J Am Soc Nephrol. 2018;29:1411-25.

20 Viswanathan G, Sarnak MJ, Tighiouart H, Muntner P, Inker L. The association of chronic kidney disease complications by albuminuria and glomerular filtration rate: a crosssectional analysis. Clin Nephrol. 2013;80:2939.

21 Stancus S, Mircescu G, Mocanu A, Capusa C, Stefan G. Metabolic acidosis of chronic kidney disease and cardiovascular disorders. Maedica. 2018;13:267-72.

22 Sebastian A, Schambelan M, Lindenfeld S, Morris RC Jr. Amelioration of metabolic acidosis with fludrocortisone therapy in hyporeninemic hypoaldosteronism. N Engl J Med. 1977;297:576-83.
23 van Nieuwkoop C, Ijpelaar DH, Bolk JH. Treating proteinuria in a diabetic patient despite hyperkalaemia due to hyporeninaemic hypoaldosteronism. Neth J Med. 2007;65:757

24 Levine DZ, Iacovovitti M, Burns KD, Slater A. Distal tubule bicarbonate reabsorption in intact and remnant diabetic kidneys. Kidney Int. 2000;57:544-9.

25 Scialla JJ, Anderson CA. Dietary acid load: a novel nutritional target in chronic kidney disease? Adv Chronic Kidney Dis. 2013;20:1419

26 Goraya N, Wesson DE. Kidney response to the spectrum of diet-induced acid stress. Nutrients. 2018;10(5):E596.

27 Passey C. Reducing the dietary acid load: how a more alkaline diet benefits patients with chronic kidney disease. J Ren Nutr. 2017; 27(3):151-60

28 Scialla JJ, Appel LJ, Astor BC, Miller ER 3rd, Beddhu S, Woodward M, et al. Estimated net endogenous acid production and serum bicarbonate in African Americans with chronic kidney disease. Clin J Am Soc Nephrol. 2011; 6:1526-32.

29 Goraya N, Simoni J, Sager L, Medias N, Wesson D. Urine citrate excretion as a marker of acid retention in patients with chronic kidney disease without overt metabolic acidosis. Kidney Int. 2019;95:1190-6.

30 Mitch WE. Metabolic and clinical consequences of metabolic acidosis. J Nephrol. 2006 Mar-Apr;19(Suppl 9):S70-5.

31 Kalantar-Zadeh K, Mehrotra R, Fouque D, Kopple JD. Metabolic acidosis and malnutrition-inflammation complex syndrome in chronic renal failure. Semin Dial. 2004;17: 455-65.

32 Mak RH. Effect of metabolic acidosis on branched-chain amino acids in uremia. Pediatr Nephrol. 1999;13:319-22.

33 Bellocq A, Suberville S, Philippe C, Bertrand $\mathrm{F}$, Perez J, et al. Low environmental $\mathrm{pH}$ is responsible for the induction of nitric-oxide synthase in macrophages. Evidence for involvement of nuclear factor-kappaB activation. J Biol Chem. 1998;273:5086-92.

34 Eustace JA, Astor B, Muntner PM, Ikizler TA, Coresh J. Prevalence of acidosis and inflammation and their association with low serum albumin in chronic kidney disease. Kidney Int. 2004;65:1031-40.

35 Brüngger M, Hulter HN, Krapf R. Effect of chronic metabolic acidosis on the growth hormone/IGF-1 endocrine axis: new cause of growth hormone insensitivity in humans. Kidney Int. 1997;51:216-21.

36 Kopple JD, Kalantar-Zadeh K, Mehrotra R Risks of chronic metabolic acidosis in patients with chronic kidney disease. Kidney Int Suppl. 2005;95:S21-7.

37 Soniklan M, Gogusev J, Zingraff J, Loric S, Quednau B, et al. Potential effect of metabolic acidosis on $\beta 2$-microglobulin generation: in vivo and in vitro studies. J Am Soc Nephrol. 1996;7:350-6
38 Mak RH. Effect of metabolic acidosis on insulin action and secretion in uremia. Kidney Int. 1998;54:603-7.

39 Bellasi A, Di Micco L, Santoro D, Marzocco S, De Simone E, et al. Correction of metabolic acidosis improves insulin resistance in chronic kidney disease. BMC Nephrol. 2016;17:158

40 Williams RS, Kozan P, Samocha-Bonet D. The role of dietary acid load and mild metabolic acidosis in insulin resistance in humans. Biochimie. 2016;124:171-7.

41 Mak RH. Effect of metabolic acidosis on hyperlipidemia in uremia. Pediatr Nephrol. 1999;13:891-3

42 Iglesias P, Diez JJ. Thyroid dysfunction and kidney disease. Eur J Endocrinol. 2009;160: 503-15.

43 Mizumoto C, Kawabata H, Uchiyama T, Sakamoto S, Kanda J, et al. Acidic milieu augments the expression of hepcidin, the central regulator of iron homeostasis. Int J Hematol. 2012;96:701-9.

44 Babitt JL, Lin HY. Mechanisms of anemia in CKD. J Am Soc Nephrol. 2012;23:1631-4.

45 Diskin CJ, Stokes TJ, Dansby LM, Radcliff L, Carter TB. Can acidosis and hyperphosphataemia result in increased erythropoietin dosing in haemodialysis patients? Nephrology. 2006;11:394-9.

46 Kim H, Kang E, Ryu H, Han M, Lee KB, Kim YS, et al. Metabolic acidosis is associated with pulse wave velocity in chronic kidney disease: results from the KNOW-CKD study. Sci Rep. 2019;9:16139.

47 Kendrick J, Shah P, Andrews E, You Z, Nowak $\mathrm{K}$, Pasch A, et al. Effect of treatment of metabolic acidosis on vascular endothelial function in patients with CKD: a pilot randomized cross-over study. Clin J Am Soc Nephrol. 2018;13(10):1463-70

48 Goraya N, Wesson D. Clinical evidence that treatment of metabolic acidosis slows the progression of chronic kidney disease. Curr Opin Nephrol Hypertens. 2019;28:267-77.

49 Wesson DE, Nathan T, Rose T, Simoni J, Tran RM. Dietary protein induces endothelin-mediated kidney injury through enhanced intrinsic acid production. Kidney Int. 2007;71:210-7.

50 Phisitkul S, Hacker C, Simoni J, Tran RM, Wesson DE. Dietary protein causes a decline in the glomerular filtration rate of the remnant kidney mediated by metabolic acidosis and endothelin receptors. Kidney Int. 2008; 73:192-9.

51 Tammaro G, Zacchia M, Zona E, Zacchia E, Capasso G. Acute and chronic effects of metabolic acidosis on renal function and structure. J Nephrol. 2018;31:551-9.

52 Nath KA, Hostetter MK, Hostetter TH. Pathophysiology of chronic tubulo-interstitial disease in rats. Interactions of dietary acid load, ammonia, and complement component C3. J Clin Invest. 1985;76:667-75.

53 Sun X, Reisz J, Molina P, Nuradin N, Tayr R, Furui $\mathrm{D}$ et al. Exogenous acid loads increase ROS production by the kidney. JASN. 2013; 24:245A. 
$54 \mathrm{Ng} \mathrm{HY}$, Chen HC, Tsai YC, Yang YK, Lee CT. Activation of intrarenal renin-angiotensin system during metabolic acidosis. Am J Nephrol. 2011;34:55-63.

55 Dobre M, Yang W, Chen J, Drawz P, Hamm LL, Horwitz E, et al. Association of serum bicarbonate with risk of renal and cardiovascular outcomes in CKD: a report from the Chronic Renal Insufficiency Cohort (CRIC) study. Am J Kidney Dis. 2013;62:670-8.

56 Gojowy D, Skiba K, Bartmanska M, Kolonko A, Wiecek A, Adamczak M. Is metabolic acidosis a novel risk factor for a long-term graft survival in patients after kidney transplantation? Kidney Blood Press Res. 2020;45(5): 702-12.

57 Park S, Kang E, Park S, Kim YC, Han SS, Ha J, et al. Metabolic acidosis and long-term clinical outcomes in kidney transplant recipients. J Am Soc Nephrol. 2017;28(6):1886-97.

58 Scialla J, Appel L, Astor BC, Miller ER 3rd, Beddhu S, Woodward M, et al. Net endogenous acid production is associated with a faster decline in GFR in African Americans. Kidney Int. 2012;82:106-12.

59 Toba K, Hosojima M, Kabasawa H, Kuwahara S, Murayama T, Yamamoto-Kabasawa K, et al. Higher estimated net endogenous acid production with lower intake of fruits and vegetables based on a dietary survey is associated with the progression of chronic kidney disease. BMC Nephrol. 2019;20:421.

60 Raphael KL, Zhang Y, Wei G, Greene T, Cheung AK, Beddhu S. Serum bicarbonate and mortality in adults in NHANES III. Nephrol Dial Transplant. 2013;28:1207-13.

61 Navaneethan SD, Schold JD, Arrigain S, Jolly SE, Wehbe E, Raina R, et al. Serum bicarbonate and mortality in stage 3 and stage 4 chronic kidney disease. Clin J Am Soc Nephrol. 2011;6:2395-402.

62 Kovesdy CP, Anderson JE, Kalantar-Zadeh K. Association of serum bicarbonate levels with mortality in patients with non-dialysis-dependent CKD. Nephrol Dial Transplant. 2009;24:1232-7.

63 Lyon D, Dunlop DM, Steward CP. The alkaline treatment of chronic nephritis. Lancet. 1931;218(5645):1009-13.

64 de Brito-Ashurst I, Varagunam M, Raftery MJ, Yaqoob MM. Bicarbonate supplementation slows progression of CKD and improves nutritional status. J Am Soc Nephrol. 2009;20: 2075-84.
65 Alva S, Divyashree M, Kamath J, Prakash PS, Prakash KS. A study on effect of bicarbonate supplementation on the progression of chronic kidney disease. Indian J Nephrol. 2020;30:91-7.

66 Phisitkul S, Khanna A, Simoni J, Broglio K, Sheather S, Rajab MH, et al. Amelioration of metabolic acidosis in patients with low GFR reduced kidney endothelin production and kidney injury, and better preserved GFR. Kidney Int. 2010;77:617-23.

67 Goraya N, Wesson D. Management of the metabolic acidosis of chronic kidney disease. Adv Chronic Kidney Dis. 2017;24:298-304.

68 Raphael KL. Metabolic acidosis and subclinical metabolic acidosis in CKD. J Am Soc Nephrol. 2018;29(2):376-82.

69 Madias NE. Metabolic acidosis and CKD progression. Clin J Am Soc Nephrol. 2021;16(2): 310-2.

70 Mahajan A, Simoni J, Sheather S, Broglio K, Rajab M, Wesson D. Daily oral sodium bicarbonate preserves glomerular filtration rate by slowing its decline in early hypertensive nephropathy. Kidney Int. 2010;78:303-9.

71 Ziomber A, Machnik A, Dahlmann A, Dietsch P, Beck FX, Wagner H, et al. Sodium-, potassium-, chloride-, and bicarbonate-related effects on blood pressure and electrolyte homeostasis in deoxycorticosterone acetatetreated rats. Am J Physiol Renal Physiol. 2008; 295:F1752-63.

72 Kunes J, Zicha J, Jelínek J. The role of chloride in deoxycorticosterone hypertension: selective sodium loading by diet or drinking fluid. Physiol Res. 2004;53:149-54.

73 Luft FC, Steinberg H, Ganten U, Meyer D, Gless KH, Lang RE, et al. Effect of sodium chloride and sodium bicarbonate on blood pressure in stroke-prone spontaneously hypertensive rats. Clin Sci. 1988;74:577-85.

74 Luft FC, Zemel MB, Sowers JA, Fineberg NS, Weinberger MH. Sodium bicarbonate and sodium chloride: effects on blood pressure and electrolyte homeostasis in normal and hypertensive man. J Hypertens. 1990;8:663-70.

75 Husted FC, Nolph KD, Maher JF. NaHCO3 and $\mathrm{NaC} 1$ tolerance in chronic renal failure. J Clin Invest. 1975;56:414-9.

76 Dobre M, Yang W, Pan Q, Appel L, Bellovich $\mathrm{K}$, Chen J, et al. Persistent high serum bicarbonate and the risk of heart failure in patients with chronic kidney disease (CKD): a report from the Chronic Renal Insufficiency Cohort (CRIC) study. J Am Heart Assoc. 2015;4: e001599.
77 Sebastian A, Frassetto LA, Sellmeyer DE, Merriam RL, Morris RC Jr. Estimation of the net acid load of the diet of ancestral preagricultural Homo sapiens and their hominid ancestors. Am J Clin Nutr. 2002;76:1308-16.

78 Rebholz CM, Coresh J, Grams ME, Steffen LM, Anderson CA, Appel LJ, et al. Dietary acid load and incident chronic kidney disease: results from the ARIC study. Am J Nephrol. 2015;42(6):427-35.

79 Goraya N, Simoni J, Jo CH, Wesson DE. Dietary acid reduction with fruits and vegetables or bicarbonate attenuates kidney injury in patients with a moderately reduced glomerular filtration rate due to hypertensive nephropathy. Kidney Int. 2012;81:86-93.

80 Goraya N, Simoni J, Jo CH, Wesson DE. Treatment of metabolic acidosis in patients with stage 3 chronic kidney disease with fruits and vegetables or oral bicarbonate reduces urine angiotensinogen and preserves glomerular filtration rate. Kidney Int. 2014;86:10318.

81 Goraya N, Simoni J, Jo CH, Wesson DE. A comparison of treating metabolic acidosis in CKD stage 4 hypertensive kidney disease with fruits and vegetables or sodium bicarbonate. Clin J Am Soc Nephrol. 2013;8:371-81.

82 Klearner G, Shao J, Biyani K, Kade M, Kierstead P, Gbur R, et al. Mechanism of action of veverimer: a novel, orally administered, nonabsorbed, counterion-free, hydrochloric acid binder under development for the treatment of metabolic acidosis in chronic kidney disease. J Pharmacol Exp Ther. 2020;375:439-50.

83 Bushinsky DA, Hostetter T, Klaerner G, Stasiv Y, Lockey C, McNulty S, et al. Randomized, controlled trial of TRC101 to increase serum bicarbonate in patients with CKD. Clin J Am Soc Nephrol. 2018;13:26-35.

84 Wesson DE, Mathur V, Tangri N, Stasiv Y, Parsell D, Li E, et al. Veverimer versus placebo in patients with metabolic acidosis associated with chronic kidney disease: a multicentre, randomised, double-blind, controlled, phase 3 trial. Lancet. 2019;393:1417-27.

85 Wesson D, Mathur V, Tangri N, Stasiv Y, Parsell D, Li E, et al. Long-term safety and efficacy of veverimer in patients with metabolic acidosis in chronic kidney disease: a multicentre, randomised, blinded, placebo-controlled, 40 week extension. Lancet. 2019;394:396-406.

86 Adrogué HJ, Madias NE. Veverimer: an emerging potential treatment option for managing the metabolic acidosis of CKD. Am J Kidney Dis. 2020 Dec;76(6):861-7. 